\title{
CHILDHOOD BLINDNESS IN THE WEST BANK AND GAZA STRIP: PREVALENCE, AETIOLOGY AND HEREDITARY FACTORS
}

\author{
MARK J. ELDER and ROMAIN DE COCK \\ Jerusalem, Israel
}

\begin{abstract}
SUMMARY
A study of all the schools for the blind in the West Bank and Gaza Strip was undertaken during 1991-2. Two hundred and five children had a complete ophthalmic examination. This represented 94\% of all children aged 5-15 years attending schools for the blind. According to WHO categories of visual loss, $63 \%$ were blind and $21 \%$ had severe visual impairment. The main causes of blindness and severe visual loss were retinal (52\%), optic atrophy $(12 \%)$, glaucoma $(9 \%)$ and cataract $(7 \%)$. Common retinal diseases included degenerative myopia, Leber's congenital amaurosis, cone dystrophy and retinitis pigmentosa. Depending on the locality, 44-85\% of these children were the product of a consanguineous marriage and a positive family history was present in $57 \%$. The minimum prevalence of childhood blindness was estimated to be $0.32 / 1000$ children. A reduction in the prevalence of blindness requires a reduction in consanguineous marriages, genetic counselling for affected families and public health measures to ensure early referral for management of cataract and glaucoma.
\end{abstract}

Impaired visual function in childhood may result from genetic, intrauterine, perinatal and postnatal factors. In industrialised countries, genetic factors are the most important cause of visual impairment ${ }^{1,2}$ accounting for approximately $50 \%$ of childhood blindness. In developing countries, corneal pathology, often associated with malnutrition or measles, is the most important cause, ${ }^{3-6}$ accounting for up to $60 \%$ of blindness.

The West Bank and Gaza Strip is home to 1.9 million Palestinian Arabs, the majority of whom are Muslim. The per capita Gross National Product is US \$1500-2000. ${ }^{7}$ Using United Nations definitions, the territories are economically one of the 'least developed' areas of the world.

From: St. John Ophthalmic Hospital, PO Box 19960, Jerusalem, Israel.

Correspondence to: Mark Elder, FRACS, FRACO, Moorfields Eye Hospital, City Road, London EC1V 2PD, UK.
Data on the causes of childhood blindness in the West Bank and Gaza Strip have not been available because there is no form of blind registration or data collection system. This study presents the findings of a study of all children aged 5-15 years attending the schools for the blind within the territories.

\section{PATIENTS AND METHODS}

The six academic blind schools of the West Bank and Gaza Strip were visited and 205 children aged from 5 to 15 years were examined. The schools catered for both residential and day students. Thirteen children were unavailable for examination; otherwise there were no exclusion criteria.

Each school was visited by the 'Outreach' facility of the St. John Ophthalmic Hospital, Jerusalem, which is a wellequipped mobile clinic. The schools' locations and patient numbers are given in Table I. Two schools had only one student each included in this study because they catered for older students. Each child was seen and examined by at least one author (M.J.E. and R.DeC.). A complete history was taken, with particular reference to family history, and previous medical and social work records were reviewed. A full ocular examination was conducted including best corrected visual acuity with Sheridan-Gardner test charts, colour vision assessment with coloured blocks, visual

Table I. The blind schools and their locations

\begin{tabular}{llr}
\hline School & Location & $\begin{array}{c}\text { No. of } \\
\text { students }\end{array}$ \\
\hline Al Shurooq & Beit Hanina, Jerusalem & 45 \\
Al Bireh & Ramallah, West Bank & 29 \\
Al Alaiyeh & Bethlehem, West Bank & 35 \\
Al Nour & Nablus, West Bank & 1 \\
Al Salaam & Beit Hanina, Jerusalem & 1 \\
UNRWA Blind School & Gaza Strip & 94 \\
& & 205 \\
\hline
\end{tabular}

UNRWA, United Nationas Relief and Work Agency. 
Table II. Anatomical site of abnormality leading to visual loss according to best corrected visual acuity in 173 children with severe visual impairment or blindness

\begin{tabular}{lccrr}
\hline & \multicolumn{2}{c}{ Categories of visual acuity } & \\
\cline { 2 - 3 } Site & $\begin{array}{c}\text { SVI } \\
(>6 / 60 \text { to } 3 / 60)\end{array}$ & $\begin{array}{c}\text { Blind } \\
(>3 / 60 \text { to NPL })\end{array}$ & SVI/blind \\
\hline Whole globe & 3 & 37 & $40(23.1)$ \\
Cornea & 5 & 5 & 5 & $(2.9)$ \\
Lens & & 7 & 12 & $(6.9)$ \\
Uvea & 28 & 1 & 1 & $(0.6)$ \\
Retina & 5 & 62 & $90(52.1)$ \\
Optic nerve & 2 & 16 & $21(12.1)$ \\
Normal globe & 43 & 2 & 4 & $(2.3)$ \\
Total & 130 & 173 & 100 \\
\hline
\end{tabular}

Values are numbers of children, with percentages in parentheses. SVI, severe visual impairment; NPL, no percentage of light.

field testing by confrontation, slit lamp biomicroscopy, cycloplegic refraction and fundoscopy. When indicated, children were sent to the base hospital for further investigations such as ultrasound, Goldmann visual fields, Farnsworth-Munsell tests and electrodiagnostic testing. Where possible, family members were examined on the same day.

We used Gilbert and Foster's classification ${ }^{8}$ and coding instructions to define the causes of childhood blindness according to anatomical categories. Among those diseases that are less easy to categorise, the following definitions were used: corneal scar included corneal dystrophies; retina included albinism, degenerative myopia, retinoblastoma and retinopathy of prematurity; optic nerve included optic nerve hypoplasia; whole eye included glaucoma and microphthalmos. The results presented are those for the child. Where there was a difference in the anatomical diagnoses between each eye the diagnosis of the best seeing eye was used. Results of visual acuity measurement were categorised according to WHO definitions, which use the best corrected acuity of the better seeing eye. The aetiologies were classified according to the WHO/PBL criteria but were only specified if the examiner was definite about the cause.

Because of a general lack of resources within the West Bank and Gaza Strip no child had been adequately assessed for low vision aids (LVAs). Therefore, as part of this study, all children were screened for full LVA assessment.

\section{RESULTS}

Two hundred and five children were examined in this study of which $109(53 \%)$ were female. The mean age was 9.1 years. Of the 205 children, $2.9 \%$ had a visual acuity of $6 / 18$ or better, $12.7 \%$ had visual impairment, $21 \%$ had severe visual impairment (SVI) and $63.4 \%$ were blind (BL). Good visual acuity per se was not necessarily associated with good visual function, as two-thirds of the children with $6 / 18$ vision, or better, had significantly reduced visual fields due to glaucoma or retinitis pigmentosa.

The anatomical sites of abnormality leading to SVI or blindness in the 173 children are given in Table II. Retinal diseases were responsible for $52 \%$, pathology of the whole globe accounted for $23 \%$ (of which $9 \%$ was due to glaucoma), optic nerve disease for $12 \%$ and cataract $7 \%$. The aetiology of the causes of SVI/BL is given in Table III.

Parental consanguinity was present in $62 \%(107 / 173)$ of children with SVI/BL: $85 \%$ (64/75) in the Gaza Strip and 44\% (43/98) in the West Bank. Parental consanguinity was defined as the union of first-degree relatives and was usually the marriage of first cousins. The prevalence of consanguinity and a family history of the same ocular diagnosis (involving a first-degree relative, usually a sibling or a parent) is detailed for each of the common diagnoses for the 173 children with SVI/BL in Table IV. Fourteen blind children were identified as having definite non-hereditary causes of blindness (trauma, toxoplasmosis, retinopathy of prematurity, infection) and 4 of these also gave a history of parental consanguinity.

There were only 3 children with a possible diagnosis of congenitally acquired rubella and one with measlesassociated blindness. One child was referred for retinal detachment surgery. Forty one per cent of children (85/ 205) were deemed suitable for formal LVA assessment.

\section{DISCUSSION}

The admission criteria for the schools for the blind in the West Bank and Gaza Strip are essentially an inability for the child to function and obtain a sighted education in a normal school. Referral can be made by a social worker or an ophthalmologist but there are no quantitative admission criteria such as a specific visual acuity or specific visual field loss.

\section{Anatomical Causes of Blindness}

The anatomical sites of visual loss are compared with those in other countries in Table V. All children had a visual acuity less than $6 / 60$ and this is similar to the other

Table III. Aetiology of visual loss according to the best corrected visual acuity in 173 children with severe visual impairment or blindness

\begin{tabular}{|c|c|c|c|}
\hline \multirow[b]{2}{*}{ Aetiology } & \multicolumn{2}{|c|}{ Categories of visual acuity } & \multirow[b]{2}{*}{ SVI/blind } \\
\hline & $\begin{array}{c}\text { SVI } \\
(>6 / 60 \text { to } 3 / 60)\end{array}$ & $\begin{array}{c}\text { Blind } \\
(>3 / 60 \text { to } N P L)\end{array}$ & \\
\hline Hereditary disease & 33 & 62 & $95(54.9)$ \\
\hline Intrauterine factor & & 2 & $2(1.2)$ \\
\hline Perinatal/neonatal factor & & 3 & 3 (1.7) \\
\hline Postnatal/infancy/childhood factor & & 9 & $9 \quad(5.2)$ \\
\hline Cannot determine & 10 & 54 & $64(37.0)$ \\
\hline Total & 43 & 130 & 173100 \\
\hline
\end{tabular}

Values are numbers of children, with percentages in parentheses. 
Table IV. Diagnosis, consanguinity and family history of the same ocular diagnosis $(n=173)$

\begin{tabular}{lcccc}
\hline & \multicolumn{3}{c}{ Numbers } & \\
\cline { 2 - 4 } Diagnosis & $n$ & $\%$ & $\begin{array}{c}\text { Consanguinity } \\
(\%)\end{array}$ & $\begin{array}{c}\text { Family history } \\
(\%)\end{array}$ \\
\hline Microphthalmos & 15 & 8.7 & 36 & 44 \\
Glaucoma & 15 & 8.7 & 69 & 23 \\
Cataract & 12 & 6.9 & 73 & 57 \\
Degenerative myopia & 22 & 12.7 & 68 & 73 \\
Leber's amaurosis & 23 & 13.3 & 55 & 50 \\
Cone dystrophy & 13 & 7.5 & 71 & 71 \\
Retinitis pigmentosa & 11 & 6.4 & 50 & 93 \\
Optic atrophy & 21 & 12.1 & 57 & 36 \\
Other & 41 & 23.7 & 56 & 42 \\
Total & 173 & $100 \%$ & & \\
\hline
\end{tabular}

studies, ${ }^{3-6,9-12}$ although the studies in Lebanon and Saudi Arabia also included acuities of $6 / 60$. The data show a pattern of diseases similar to that found in the United States and the United Kingdom (developed countries) except that a higher proportion of visual loss is due to glaucoma (9\% vs. 0 and $2 \%$ respectively). This contrasts with Africa, which has similar economic circumstances to the West Bank and Gaza Strip. Glaucoma is reported to be an important cause of childhood blindness in Saudi Arabia, Jordan and Lebanon $(14 \%, 15 \%$ and $18 \%) .{ }^{11-13}$ These are countries with predominantly Arab populations and a high degree of consanguinity. ${ }^{11-13}$ Compared with other countries, the West Bank and Gaza Strip have a high proportion of SVI/BL due to retinal disease (52\%). The major retinal causes were Leber's congenital amaurosis $(n=23)$, degenerative myopia $(n=22)$, cone dystrophy $(n=13)$, retinitis pigmentosa $(n=11)$ and retinopathy of prematurity $(n=3)$. There was little SVI/BL due to rubella or measles. This contrasts with East and West Africa where the incidence of measles-associated blindness is between $27 \%$ and $34 \% .^{3-6}$ This is probably due to an effective vaccination programme or to a relative lack of malnutrition. In a study in the West Bank, $49 \%$ of young children were fully vaccinated, $46 \%$ were partially vaccinated and only $5 \%$ had not been immunised. ${ }^{14}$

\section{Consanguinity}

Levels of parental consanguinity are very high in this study (62\%) but are similar to studies of blind children undertaken in other Middle East countries such as Saudi Arabia (56\%), ${ }^{12}$ Lebanon $(56 \%)^{11}$ and Jordan $(67 \%) .{ }^{13}$ These findings are in marked contrast to studies undertaken in Europe and Africa where the figures are 0 in Scot- land, ${ }^{10} 1.7 \%$ in Ireland $^{15}$ and $7.8 \%$ in Malawi. ${ }^{16}$ The prevalence of consanguinity in the general population of the West Bank and Gaza Strip is unknown, although a study of handicapped children in Gaza Strip showed a prevalence of 59\%. ${ }^{17}$ In Lebanon, Abou Daoud ${ }^{18}$ showed that $20 \%$ of all marriages are consanguineous, usually between first cousins. The Lebanese study of childhood blindness $^{11}$ found consanguineous marriages in the parents of $28 \%$ of children with acquired SVI/BL; this compares with $14 \%$ in Saudi Arabia, ${ }^{12} 33 \%$ in Jordan ${ }^{13}$ and $29 \%(4 / 14)$ in this study.

Levels of consanguinity were higher in the Gaza Strip than the West Bank (85\% vs. 44\%). The reasons for this are not clear but are probably multifactorial.

Consanguinity allows the expression of recessive genes and this may explain the high numbers of children in this study with known recessive conditions such as Leber's amaurosis (13\%), cone dystrophy (8\%), retinitis pigmentosa $(6 \%)$ and albinism (3\%). This is in contrast to findings in Scotland where a total of $7 \%$ of childhood blindness was due to recessive genes; ${ }^{10}$ however, it is in accordance with data from Lebanon, ${ }^{11}$ where $65 \%$ of childhood blindness was estimated to be autosomal recessive.

\section{Prevalence of Blindness}

The minimum prevalance of blindness in school-age children can be estimated using standard demographic data ${ }^{19}$ dating from 1992. The population of the West Bank and East Jerusalem was 1202000 of whom 335358 (27.9\%) were aged 5-15 years, 98 of whom had a visual acuity of less than 6/60. The population of Gaza Strip was 714800 of whom $203003(28.4 \%)$ were aged 5-15 years, 75 of whom had an acuity of less than $6 / 60$. Therefore the minimum prevalence of school-age SVI/BL is estimated to be 0.29 and $0.37 / 1000$ respectively with a mean of $0.32 / 1000$ children. The above calculations assume, however, that all blind children have been identified and attend schools for the blind. The regular school screening programmes are likely to detect most children with severe visual loss who are otherwise normal. Due to the lack of programmes for integrated education and the legal requirement to attend school it is probable that most severely visually impaired children will attend schools for the blind. However, children with multiple handicaps will not be represented. The prevalence of school-age blindness calculated from data obtained from this study is therefore a minimum estimate.

\section{Possible Control Measures}

To reduce the prevalence of childhood blindness in the

Table V. Anatomical site of childhood blindness and severe visual impairment by percentage

\begin{tabular}{|c|c|c|c|c|c|c|}
\hline $\begin{array}{l}\text { Location: } \\
\text { Year: }\end{array}$ & $\begin{array}{c}\text { USA }^{9} \\
\text { (16 states) } \\
1970\end{array}$ & $\begin{array}{c}\text { Edinburgh }^{10} \\
(n=99) \\
1987\end{array}$ & $\begin{array}{c}\text { East Africa }{ }^{3-6} \\
(n=1712) \\
1970-9\end{array}$ & $\begin{array}{l}\text { Lebanon }^{11} \\
(n=203) \\
1973\end{array}$ & $\begin{array}{l}\text { Saudi Arabia }{ }^{12} \\
\quad(n=105) \\
1985\end{array}$ & $\begin{array}{l}\text { West Bank and Gaza Strip } \\
\qquad \begin{array}{c}n=173) \\
1992\end{array}\end{array}$ \\
\hline Corneal scar/phthisis & 2 & 1 & 62 & 5 & 4 & 5.5 \\
\hline Lens & 13 & 12 & 8 & 17 & 29 & 7 \\
\hline Uvea & 3 & 1 & 4 & 0 & & 0.5 \\
\hline Retina & 33 & 36 & 2.5 & 28 & 39 & 52 \\
\hline Optic nerve & 9 & 16 & 7.5 & 6 & 4 & 12 \\
\hline Glaucoma & 0 & 2 & 0.3 & 18 & 14 & 9 \\
\hline Whole eye/others unknown & 40 & 31 & 15.7 & 22 & 10 & 14 \\
\hline
\end{tabular}


West Bank and Gaza Strip there is a particular need to reduce the incidence of childhood blindness from hereditary causes. This may be achieved by reducing the incidence of consanguineous marriages and by providing genetic counselling to families with blind children or a family history of blindness. Counselling may be of particular benefit to parents with existing blind children with autosomal dominant or X-linked conditions. ${ }^{20}$ However, at least $29 \%$ of all children with SVI/BL had known recessive diseases. Counselling these families may prevent further affected siblings being conceived. However, there are currently neither the resources nor the cultural acceptability for prenatal diagnosis or termination of pregnancy $^{21}$ which would justify screening programmes. Reducing the incidence of consanguineous marriages would also reduce the incidence of recessive blindness, but this would be difficult to achieve, mainly because it is so socially acceptable. Congenital and infantile glaucoma and congenital cataract need particular measures to ensure early identification and optimal treatment, as together they represent $16 \%$ of all children with SVI/BL.

The authors are grateful to Sir Godfrey Milton-Thompson, the Order of St. John and the Royal New Zealand Blind Foundation for providing the resources for this study and to Clare Gilbert, FRCS, and Allen Foster, FRCS, for their helpful comments.

Key words: Blind school, Cataract, Consanguinity, Glaucoma, Leber's amaurosis, Microphthalmia, Myopia.

\section{REFERENCES}

1. Sorsby A. The incidence and causes of blindness in England and Wales 1948-62. London: HMSO, 1966.

2. Fraser GR, Friedmann AI. The causes of blindness in childhood: a study of 776 children with severe visual handicaps. Baltimore: Johns Hopkins Press, 1967.

3. Sauter JJ. Xerophthalmia and measles in Kenya. Groningen: Van Denderen, 1976.

4. Sauter JJ. Causes of blindness in 19 schools for blind in Tanzania: final report for Ministry of Health. Dar-es-Salaam 1978.

5. Sandford-Smith JH, Whittle HC. Corneal ulceration following measles in Nigerian children. $\mathrm{Br} \mathrm{J}$ Ophthalmol $1979 ; 63: 720-4$.
6. Olurin O. Aetiology of blindness in Nigerian children. Am J Ophthalmol 1970;70:533-40.

7. Health in Judea, Samaria and Gaza 1991. State of Israel, Ministry of Health, 1991.

8. Gilbert C, Foster A, Thylefors B, Nigrel A. Childhood blindness: a new form for recording causes of visual loss in children. WHO Bulletin (in press).

9. Kahn HA, Moorhead HB. Statistics on blindness in the model reporting area, 1969-1970. Publication no. NIH 73427. Washington, DC: US Government Printing Office, 1973.

10. Phillips CI, Levy AM, Newton M, Stokoe LN. Blindness in schoolchildren: importance of hereditary, congenital cataract and prematurity. Br J Ophthalmol 1987;71:578-84.

11. Baghdassarian SA, Tabbara KF. Childhood blindness in Lebanon. Am J Ophthalmol 1975;79:827-30.

12. Tabbara KF, Badr IA. Changing patterns of childhood blindness in Saudi Arabia. Br J Ophthalmol 1985;69:312-5.

13. Al-Salem M, Rawashdeh N. Patterns of childhood blindness and partial sight among Jordanians in two generations. J Pediatr Ophthalmol Strabismus 1992;29:361-5.

14. Shahin M, Shahin VA. A baseline study on selected health and health related conditions of designated villages in the Hebron area. In: Health in the West Bank and the Gaza Strip: an annotated bibliography. 2nd ed. Health Development Information Project, 1992:4.

15. Goggin M, O'Keefe M. Childhood blindness in the Republic of Ireland: a national survey. Br J Ophthalmol 1991;75: 425-9.

16. Chirambo MC. Causes of blindness among students in blind school institutions in a developing country. Br J Ophthalmol 1976;60:655-68.

17. Saunders CA. A study of handicapped conditions affecting children and a case finding intervention in the refugee camp population of the Gaza Strip. In: Health in the West Bank and the Gaza Strip: an annotated bibliogaphy. 2nd ed. Health Development Information Project, 1992:59.

18. Abou Daoud KT. Diabetes mellitus in a Lebanese population group. Am J Epidemiol 1969;89:644-50.

19. The National Health Plan for the Palestinian People. Interim Report, September 1992. Jerusalem: The National Health Plan Commission, 1992.

20. Phillips CI, Stokoe NL. An ophthalmic genetics clinic. Trans Ophthalmol Soc UK 1975;95:472-6.

21. Jay B. Causes of blindness in schoolchildren. BMJ 1987;294:1183-4. 